\title{
O ciclo infinito de Matthew Barney
}

\author{
Catarina Maia
}

Os anos 90 do século XX aceleraram e tornaram mais complexas as ligações entre a performance e os diversos media. A partir desta década, as experiências de miscigenação adquirem uma maior consciência da sua densidade e das suas possibilidades expressivas. A internet surge neste contexto como um importante suporte de armazenamento e de divulgação, a ponto de se tornar para muitos artistas uma forma especifica de comunicação. Sendo capaz de transmitir som e imagens em movimento, bem como de efectuar trocas em tempo real, a internet revelou-se um caminho atractivo, pleno de oportunidades para o campo do teatro e da performance'.

Neste contexto, o trabalho criativo de Matthew Barney é especialmente interessante, pois além de reflectir a tendência crescente para a miscigenação, ao integrar a pintura, a fotografia, a escultura e o vídeo, pensa também as consequências dessas práticas na própria performance contemporânea. Assim sucede, sobretudo no que diz respeito à relação entre o evento gravado e 0 acontecimento ao vivo. Esta questão é principalmente importante, uma vez que nos debruçaremos aqui, ainda que de forma sucinta, sobre o sítio que alberga uma das mais recentes e mais aclamadas obras de Barney: o Ciclo Cremaster.

Comecemos por uma breve apresentação. 0 Ciclo é composto por uma série de cinco filmes (ou instalações, como por vezes se thes refere o autor) cuja produção se estendeu por quase uma década, começando com Cremaster 4 (1994), seguindo-se Cremaster 1 (1996), Cremaster 5 (1997), Cremaster 2 (1999), terminando finalmente com Cremaster 3 (2002). Barney assumiu uma trajectória geográfica em direcção ao Leste: a série iniciase no Noroeste americano e acaba na Europa Oriental, Franklin Furnace (http://www.franklinfurn ace.org/), autor de um trabalho longo e reconhecido neste campo. passando por lugares como o Bronco Stadium em Boise a llha de Man, o clássico nova-iorquino da Art Déco - o edificio Chrysler - e o Guggenheim Museum de New York (onde teria lugar a grande exposição Cremaster), entre outros espaços.
Cremaster adopta como ponto de partida conceptual as primeiras seis semanas do processo de desenvolvimento de um embrião. Durante este tempo, o feto recém-formado é puro potencial, nem feminino nem masculino; move-se no campo da indiferenciação sexual. Livre de pronomes ou de indicadores anatómicos que o definam, imaginase capaz da suspensão por tempo indeterminado neste estado superior de liberdade. Mas a marcação do sujeito revela-se inevitável... 0 que parece estar aqui em causa é algo de essencial. Para usar a expressão de Deleuze e Guattari, assistiríamos à passagem do estado intensivo para o estado extensivo, isto é, à passagem de uma ordem de signos ambíguos para um regime de signos modificáveis mas determinados. É este o impasse fundamental que marca a abertura do projecto.

0 trabalho de Barney parte, como outros trabalhos anteriores (relembro Ottoshaft), de uma base simultaneamente biológica, anatómica, psicanalítica, autobiográfica, histórica e mitológica, para criar uma estrutura polissémica. Um objecto centrífugo, que aponta em demasiadas direcções, acomete-se em demasiadas relações. Tudo é activo, e agido, reagindo no sistema. Está tudo em utilização e em função, de modo que quando consideramos o conjunto da representação, somos levados a constatar a complexidade das redes com que a obra se cobre: a correia de signos salta constantemente dum elemento para outro, irradiando em todas as direcções, conectando palavras, corpos, coisas e afectos, conotando grafias.

Como nos eventos de cariz performativo, não estamos perante uma linearidade ou uma coerência (pelo menos não uma coerência externa). Perspectivado desta forma, o Ciclo vai ao encontro de uma cronologia interna, acabando por se organizar por ordem numérica, independente da sequência de lançamento de cada filme. Assim, Cremaster 1 representará a fase mais indiferenciada desse processo; Cremaster 5, a mais diferenciada; ou pela ordem que foi feito $(4,1,5,2,3)$. É muito interessante 

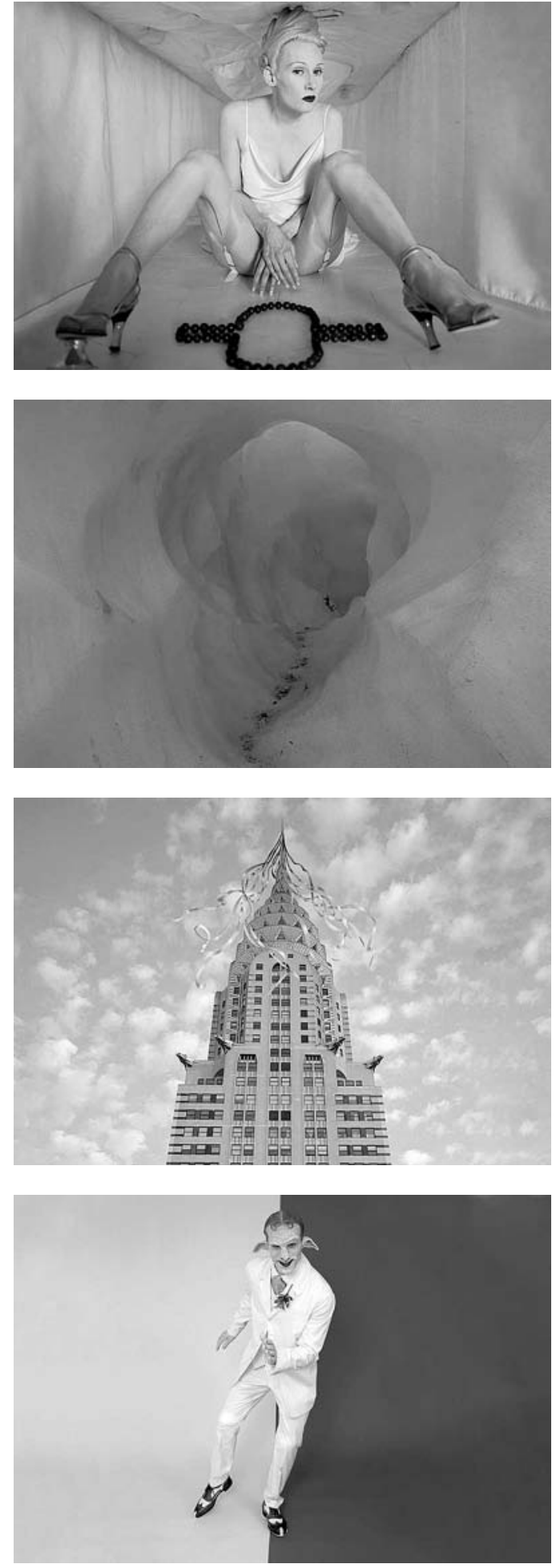

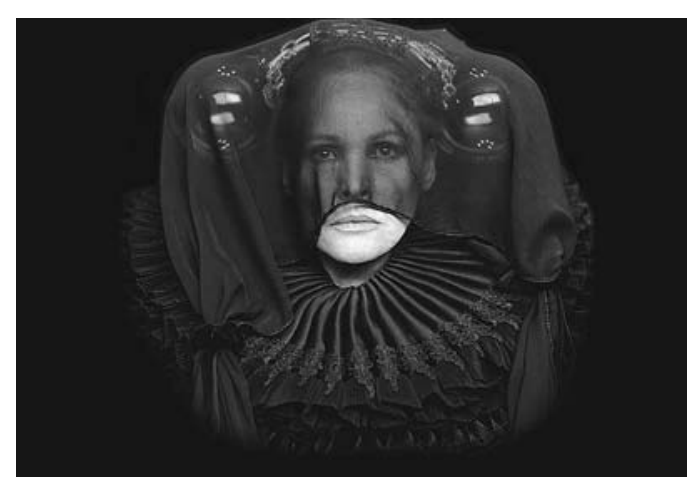

fazer esta experiência, porque se observa muito bem a complexificação progressiva das personagens: com o desenvolvimento do Ciclo, vai emergindo uma série de personagens, cada uma enformando (e antecipando) a evolução da seguinte.

A intensificação destas contiguidades sustenta formas mais intrincadas de desenvolvimento das personagens, mas não no sentido convencional. Para Barney, uma personagem pode incorporar o espaço, o guarda-roupa, assim como as atitudes e as sensibilidades. Uma personagem tanto pode ser um sátiro, um aprendiz de maçonaria, como uma ilha celta, uma casa de ópera barroca, ou um coro de sessenta raparigas. Enquanto "vectores" ou "compulsões", nomes que Barney também refere para descrever as personagens deste Ciclo, estas nascem de personificações, de topografias interiores não exploradas. Deste modo, elas são todas facetas de um mesmo organismo, todas são mutações de um sistema em permanente desequilibrio. As personagens derivam, errantes, de excerto em excerto, seja entre aspectos físicos e sexuais diferentes; apresentam-se sempre sós e reguladas por uma história que, em certa medida, as antecede e as ultrapassa. Elas dão forma a uma luta de tensões inerentes à força descontínua das coisas.

Se concentrarmos a nossa atenção nas formas de representação, a obra de Barney é uma exploração dos limites absolutos da actividade performativa dos corpos, considerados como objectos de um processo de metamorfose infinita ou mesmo claramente infinitizada. 0 próprio autor é um performer que encarna muitas personagens ao longo do Ciclo: é simplesmente impressionante ver o seu esforço imenso como corporeidade. Trata-se de uma tentativa de alcançar um nivel porvir, um esforço para transcender o status quo, para superar as restrições presenciais do "eu". Poderiamos então dizer que, nestas experiências de Barney, a performatividade pura suplanta as várias hipóteses narrativas, transforma-as inclusive em paródia, para fazer
Marti Domination como "Goodyear" em Cremaster 1 (1996).

\section{Ursula Andress} como "The Queen of Chain" em Cremaster 5 (1997). $>$

$<$

Loughton Field Cremaster 4 (1994).

0 edificio Chrysler, onde decorre a maior parte da acção em Cremaster 3 (2002).

Matthew Barney como "Loughton Candidate" em Cremaster 4 (1994).

${ }^{2}$ Gary Gilmore (Cremaster 2), "The Entered Apprentice" (Cremaster 4), "Diva, Giant and Magician" (Cremaster 5) 

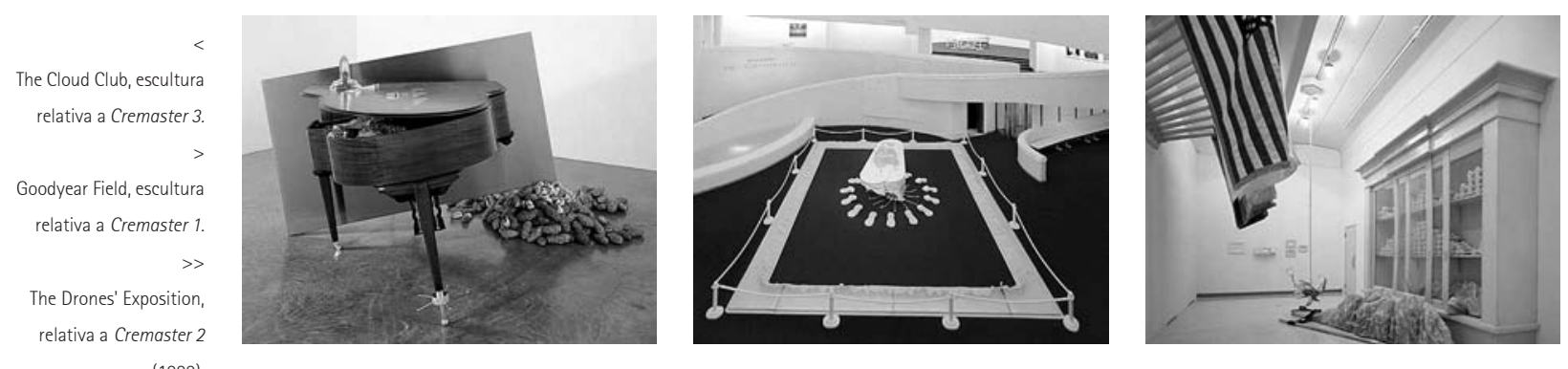

Os cinco Chrysler Imperial

1967 que representam cada

um uma das cinco partes do Ciclo numa encenação

de um Demolition Derby

em Cremaster 3.

>>>
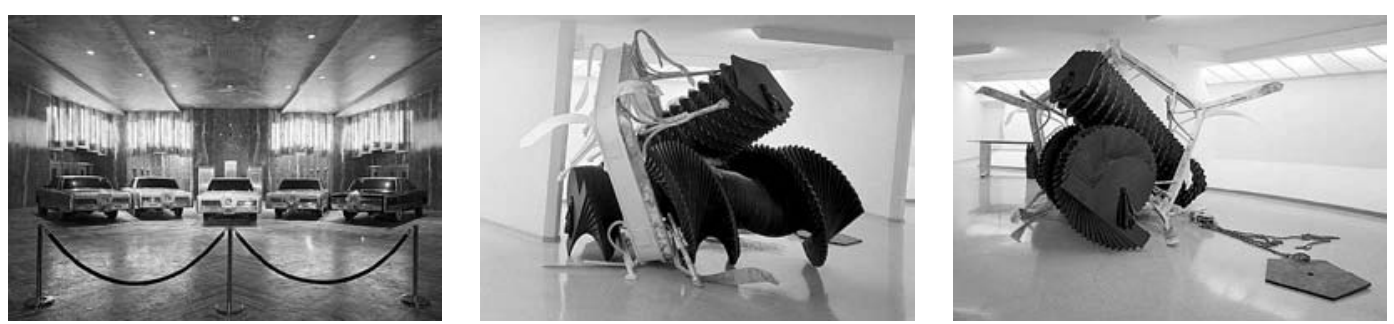

Jachin e Boaz, esculturas

relativas a Cremaster 3 . Alusões às duas colunas que Hiram Abiff desenhou para o Templo de Salomão - detêm ainda um grande simbolismo nas práticas

maçónicas. Cf. http://www.nels.com/ mason/systb52.html

emergir, limpida, uma outra, única e incomensurável narrativa, seguramente a narrativa mítica que abarca todo o projecto e o aproxima das mitificações surrealistas, as quais vinham já desde as décadas iniciais do século $X X$, trilhando um caminho vanguardista, justamente entre 0 cinematográfico e o performativo que aqui reencontramos hipostasiado.

Uma vez que não existe uma edição em dvd, o conhecimento do projecto assenta em grande medida na pesquisa através da internet. Mas é importante olhar para o sitio www.cremaster.net como uma porta aberta, como apelo ao relacionamento directo com a obra. A página inicial do sítio abre com os cinco símbolos correspondentes aos cinco filmes que compõem o Ciclo Cremaster, dirigindonos cada um para páginas diferentes, ligadas entre si pelo botão Cycle (comum a todas as páginas), o qual nos permite navegar facilmente entre elas. Na verdade, todas as páginas principais $(1,2,3,4$ e 5$)$ têm uma estrutura em tudo semelhante, pois mantêm as mesmas oito categorias: Synopsis, Characters, Sculpture, Trailer, Screenings, Cycle, Menu. Apenas muda a grande imagem que serve de fundo. 0 desenho é muito simples e funcional, opondo-se um pouco ao carácter barroco "des"-funcional que todo o Ciclo lembra e convoca. Neste sentido, é fácil reconhecer e assimilar, quase num primeiro olhar, o tipo de informação que aqui podemos encontrar. 0 sítio não contém reproduções das séries (apenas os trailers), nem sequer muitas imagens, fotográficas ou videográficas. No caso de Sculpture, as fotografias das esculturas são relativamente escassas, embora com excelente definição. Mas o sitio fornece-nos uma informação detalhada e actualizada sobre os locais e datas de exibição da totalidade do Ciclo, a que se junta a bibliografia disponivel sobre a obra. Talvez seja a página relativa a Characters o momento mais precioso deste sítio. Trata da forma como o autor desenvolve as personagens e oferece-nos engenhosos esquemas de ligação entre elas. Esta esquematização não está sequer no excelente livro editado a partir da exposição realizada no Museu Guggenheim de Nova lorque (clicando em Exhibitions temos uma ligação directa para a página do museu integralmente dedicada ao Ciclo). 0 Menu abre para uma série de categorias (Books, Music/dvd, Credits, Biographies, Bibliography, Links) muito pertinentes para o estudo da obra, pois disponibilizam, organizam e facilitam a pesquisa de informação sobre toda a equipa que ajudou à concretização deste grande contra-épico da contemporaneidade, com remissões para tudo o que vai sendo lançado ou se relaciona com o Ciclo. A par deste lado funcional, o visitante tem acesso ao fascínio visual, quase licencioso, que no sítio nos faz antever a possibilidade de êxtase face ao Ciclo infinito de Matthew Barney.

\section{Referência bibliográfica}

DELEUZE, Gilles / GUATTARI, Félix (2004), O anti-Édipo: capitalismo e esquizofrenia; trad. Joana Moraes Varela e Manuel Maria Carrilho, Lisboa: Assírio \&t Alvim. 